\title{
Adsorption of Methyl Iodide on Reduced Silver-Functionalized Silica Aerogel: Kinetics and Modeling
}

\author{
Siqi Tang ${ }^{1,1}$, Seungrag $\mathrm{Choi}^{1}$, Yue $\mathrm{Nan}^{1}$, and Lawrence Tavlarides ${ }^{1}$ \\ ${ }^{1}$ Syracuse University
}

June 18, 2020

\begin{abstract}
The low concentration methyl iodides $\left(\mathrm{CH}_{3} \mathrm{I}\right)$ adsorption process on reduced silver-functionalized silica aerogel $\left(\mathrm{Ag}^{0}\right.$-Aerogel $)$ was studied. The kinetic data were acquired using a continuous flow adsorption system. Because the corresponding physical process was observed, the shrinking core model (SCM) was modified and applied. An average $\mathrm{CH}_{3} \mathrm{I}$ pore diffusivity was calculated, the $\mathrm{CH}_{3} \mathrm{I}-\mathrm{Ag}^{0}$-Aerogel reaction was identified as a 1.37 order reaction instead of first order reaction, and the $\mathrm{n}^{\text {th }}$ order reaction rate constant was determined. This modified SCM significantly increases the accuracy of adsorption behavior prediction at low adsorbate concentration. Modeling results indicate that the overall adsorption process is controlled by the pore diffusion. However, at low adsorbate concentration $(<100 \mathrm{ppbv})$, the $\mathrm{CH}_{3} \mathrm{I}$ adsorption is limited to the surface reaction due to the low uptake rate in a predictable time period.
\end{abstract}

Adsorption of Methyl Iodide on Reduced Silver-Functionalized Silica Aerogel: Kinetics and Modeling

Siqi Tang, Seungrag Choi, Yue Nan* and Lawrence L. Tavlarides

Department of Biomedical and Chemical Engineering, Syracuse University, 329 Link Hall, Syracuse, NY 13244, USA

\begin{abstract}
The low concentration methyl iodides $\left(\mathrm{CH}_{3} \mathrm{I}\right)$ adsorption process on reduced silver-functionalized silica aerogel $\left(\mathrm{Ag}^{0}\right.$-Aerogel $)$ was studied. The kinetic data were acquired using a continuous flow adsorption system. Because the corresponding physical process was observed, the shrinking core model (SCM) was modified and applied. An average $\mathrm{CH}_{3} \mathrm{I}$ pore diffusivity was calculated, the $\mathrm{CH}_{3} \mathrm{I}-\mathrm{Ag}^{0}$-Aerogel reaction was identified as a 1.37 order reaction instead of first order reaction, and the $\mathrm{n}^{\text {th }}$ order reaction rate constant was determined. This modified SCM significantly increases the accuracy of adsorption behavior prediction at low adsorbate concentration. Modeling results indicate that the overall adsorption process is controlled by the pore diffusion. However, at low adsorbate concentration $(<100 \mathrm{ppbv})$, the $\mathrm{CH}_{3} \mathrm{I}$ adsorption is limited to the surface reaction due to the low uptake rate in a predictable time period.
\end{abstract}

\section{Topical Heading}

Separations: Materials, Devices and Processes

\section{Keywords}

Adsorption, iodine removal, separation, silver aerogel, shrinking core model 


\section{Introduction}

Nuclear power has been widely used since the $20^{\text {th }}$ century for its low emission rate of air pollutants. ${ }^{1-3}$ However, multiple radioactive isotopes, including radioactive Iodine $\left({ }^{129} \mathrm{I}\right)$, are produced in the uranium fission. ${ }^{4,5}$ During aqueous reprocessing of the nuclear waste, ${ }^{85} \mathrm{Kr},{ }^{14} \mathrm{C},{ }^{129} \mathrm{I}$, and ${ }^{3} \mathrm{H}$ are released to the offgas streams. The off-gas streams include dissolver off-gas (DOG), cell off-gas (COG), waste off-gas (WOG) and vessel off-gas (VOG). ${ }^{6}$ According to Bruffey et al. ${ }^{6,7}$, approximately $95 \%$ - $98 \%$ of iodine is contained in DOG, remaining iodine (in $\mathrm{I}_{2}$ and organic iodides form) exists in VOG, and VOG flow rate is $100 \times$ higher than that of DOG. Therefore, unlike the ppm level in DOG, the iodine concentration in VOG decreases to below $100 \mathrm{ppbv}$. Although only trace amount of iodine exists in VOG, the off-gas cannot be emitted directly into atmosphere, and the emissions are governed by 10 CFR 20, 40 CFR 61 and 40 CFR 190. ${ }^{8-10}$ The composition of the organic iodides existing in VOG varies from methyl iodide $\left(\mathrm{CH}_{3} \mathrm{I}\right)$ to iodododecane $\left(\mathrm{C}_{12} \mathrm{H}_{25} \mathrm{I}\right)$ and among 12 different organic iodides, $\mathrm{CH}_{3} \mathrm{I}$ and $\mathrm{C}_{12} \mathrm{H}_{25} \mathrm{I}$ were reported to be the two most abundant components. ${ }^{6,11,12}$

Multiple silver containing materials, including macroreticular resins, silver impregnated alumina $(\operatorname{Ag} A)$, silver exchanged faujasite $(\mathrm{AgX})$, hydrogen-reduced silver exchanged mordenite $\left(\mathrm{Ag}^{0} \mathrm{Z}\right)$ and reduced silverfunctionalized silica aerogel $\left(\mathrm{Ag}^{0}\right.$-Aerogel $)$, have been developed and studied for $\mathrm{I}_{2}$ and organic iodides adsorption. ${ }^{4,13-18}$ The reason for selecting silver-containing materials over traditional liquid scrubbing methods is concluded to be stronger Ag-I bond and solid form, therefore, higher removal efficiency and lower operation cost. ${ }^{4,19-22}$ Among these silver-containing materials, $\mathrm{Ag}^{0} \mathrm{Z}$ and $\mathrm{Ag}^{0}$-Aerogel have been studied continuously in US national laboratories and universities for their high iodine removal efficiency and relatively greater resistance to aging caused by potential contaminants in VOG and DOG $\left(\mathrm{NO}_{\mathrm{x}}\right.$, water vapor, air). ${ }^{12,17,23} \mathrm{Nan}$ et.al ${ }^{16,19}$ have conducted the single layer adsorption experiments of $\mathrm{I}_{2}$ on $\mathrm{Ag}^{0} \mathrm{Z}$ and reported approximately $12 \mathrm{wt} \% \mathrm{I}_{2}$ adsorption capacity at $423 \mathrm{~K}$. Deep-bed adsorption of $\mathrm{I}_{2}$ and $\mathrm{CH}_{3} \mathrm{I}$ on $\mathrm{Ag}^{0} \mathrm{Z}$ at both ppb and ppm level have been studied by Jubin et al. ${ }^{14,18}$, Bruffey et al. ${ }^{6,24}$ and Soelberg and Watson ${ }^{25,26}$, indicating the adsorption rate of $\mathrm{CH}_{3} \mathrm{I}$ is lower than that of $\mathrm{I}_{2}$.

Deep-bed $\mathrm{Ag}^{0}$-Aerogel adsorption experiments of $\mathrm{CH}_{3} \mathrm{I}$ and $\mathrm{I}_{2}$ under the VOG conditions were conducted in multiple US national laboratories. Strachan et al. ${ }^{27}$ performed 4.2 ppmv $\mathrm{I}_{2}$ adsorption experiments at 150 , concluding that fresh $\mathrm{Ag}^{0}$-Aerogel was able to remove $\mathrm{I}_{2}$ for at least $99.99 \%$ efficiency and observing that $\mathrm{Ag}^{0}$-Aerogel changed from black to a brown, earth-tone color during the adsorption experiment. Soelberg and Watson ${ }^{28,29}$ conducted $\mathrm{I}_{2}$ adsorption on $\mathrm{Ag}^{0} \mathrm{Z}$ and $\mathrm{Ag}^{0}$-Aerogel at 150 with $\mathrm{NO}_{\mathrm{x}}$ and $\mathrm{H}_{2} \mathrm{O}$ present, with $\mathrm{I}_{2}$ concentration ranging from 2 to $370 \mathrm{ppmv}$. Their results indicated, at similar conditions, $\mathrm{Ag}^{0}$-Aerogel obtained higher resistance to $\mathrm{NO}_{\mathrm{x}}$ than $\mathrm{Ag}^{0} \mathrm{Z}$ did and, therefore, showed higher removal efficiency in deepbed adsorption experiments. In addition, deep-bed $\mathrm{CH}_{3} \mathrm{I}$ adsorption studies have also been conducted by Bruffey and Jubin ${ }^{7}$, Jubin et al. ${ }^{14}$ and Soelberg and Watson ${ }^{17}$. $\mathrm{Ag}^{0}$-Aerogel showed an adequate capability to adsorb $\mathrm{CH}_{3} \mathrm{I}$ at various conditions such as ppb or ppm level concentrations and with or without the presence of $\mathrm{NO}_{\mathrm{x}}$. The penetration depth of $\mathrm{CH}_{3} \mathrm{I}$ in the column was measured to be 3-7 cm, depending on the $\mathrm{CH}_{3} \mathrm{I}$ and $\mathrm{NO}_{\mathrm{x}}$ concentration; and the decontamination factor (DF), defined as inlet concentration of desired adsorbed species (eg. $\mathrm{I}_{2}$ and $\mathrm{CH}_{3} \mathrm{I}$ ) over outlet concentration, can reach approximately 1000 .

The detailed organic iodides- $\mathrm{Ag}$ reaction mechanism was not conclusive. Scheele et al. ${ }^{30}$ proposed several possible reactions between $\mathrm{Ag}$ and $\mathrm{CH}_{3} \mathrm{I}$ in $\mathrm{Ag}^{0} \mathrm{Z}$ :

In these proposed reactions, organic compounds are generated in gas form and only iodine is captured by silver. The generated $\mathrm{CH}_{3} \mathrm{OCH}_{3}$ (dimethyl ether) and $\mathrm{CH}_{3} \mathrm{OH}$ (methanol) were observed by Soelberg and Watson ${ }^{25}$ and the desorption of $\mathrm{C}_{2} \mathrm{H}_{6}$ in similar reactions was suggested by $\mathrm{Zhou}$ et al ${ }^{31}$. With the presence of $\mathrm{NO}_{\mathrm{x}}$ in the gas stream, other organic compounds such as $\mathrm{CH}_{3} \mathrm{NO}_{2}$ (nitromethane) and $\mathrm{C}_{3} \mathrm{H}_{9} \mathrm{NO}$ (3-amino1-propanol) were also detected. ${ }^{26}$ Assuming similar reactions happen between $\mathrm{Ag}^{0}$-Aerogel and $\mathrm{CH}_{3} \mathrm{I}$ and only iodine is left in $\mathrm{Ag}^{0}$-Aerogel pellets, the maximum iodine capture capacity for $\mathrm{I}_{2}$ should be the same as that for $\mathrm{CH}_{3} \mathrm{I}$. 
Limited by the nature of deep-bed adsorption experiments, the mass of deep-bed adsorption column cannot be measured continuously and most of the curves were composed by discrete data points instead of realtime data. Therefore, as complements to the deep-bed adsorption experiments, single-layer $\mathrm{CH}_{3} \mathrm{I}$ adsorption experiments on $\mathrm{Ag}^{0}$-Aerogel were conducted in the present work. One of the purposes of performing the single-layer adsorption experiments is determining the pore diffusivity and reaction rate constant and these parameters can be related and applied for column adsorption modeling. ${ }^{32-34}$

In the single-layer adsorption experiments, $\mathrm{Ag}^{0}$-Aerogel was placed in a tray connected to a microbalance, enabling real-time and high-precision measurement of the mass change. The $\mathrm{CH}_{3} \mathrm{I}$ concentrations selected were 113, 266, 1130 and $10400 \mathrm{ppbv}$; temperature was 150 , same as the experiments described above; and gas flow rate was set to be $500 \mathrm{sccm}$ in order to satisfy $1.1 \mathrm{~m} / \mathrm{s}$ superficial gas velocity suggested by Nan et al. ${ }^{19}$ The adsorption kinetic data at various $\mathrm{CH}_{3} \mathrm{I}$ concentrations were obtained and used to evaluate the pore diffusivity and reaction rate of $\mathrm{CH}_{3} \mathrm{I}$ in $\mathrm{Ag}^{0}$-Aerogel. To explain the inconsistency of reaction rate constants at different concentrations, an $\mathrm{n}^{\text {th }}$ order shrinking core model was applied and the modeling results were used to improve the predictions of adsorption behavior at various $\mathrm{CH}_{3} \mathrm{I}$ concentrations.

\section{Materials and Methods}

\section{Silver-Functionalized Silica Aerogel}

Reduced silver-functionalized silica aerogel $\left(\mathrm{Ag}^{0}\right.$-Aerogel $)$ was obtained from the Pacific North National Laboratory (PNNL) in 2017. It was first developed there for gaseous iodine capturing in nuclear waste treatment. ${ }^{35,36}$ The $\mathrm{Ag}^{0}$-Aerogel pellets are primarily black; the shape and size are arbitrary and some of the pellets contain certain yellow areas which may be due to unevenly coated silver in the manufacturing process. The particle radius is approximately $0.1 \mathrm{~cm}$. Reported by Jubin et al. ${ }^{14}$, the bulk density of the pellet is $0.54 \mathrm{~g} / \mathrm{cm}^{3}$ and $0.62 \mathrm{~g} / \mathrm{cm}^{3}$ for 'as-received material' and 'post-run material' respectively. For the modeling work to be discussed in the following sections, an average value of $0.58 \mathrm{~g} / \mathrm{cm}^{3}$ was used. The maximum iodine loading capacity reported ranged from 33 to $47 \mathrm{wt} \%^{27,29,37}$. To achieve accurate modeling results, the iodine loading capacity was measured to be approximately $37 \mathrm{wt} \%$ using the continuous flow adsorption system.

\section{Continuous Flow Adsorption System}

The continuous flow adsorption system was used for iodine and water vapor adsorption on multiple materials previously by Nan et al. ${ }^{19,38,39}$ and Lin et al. ${ }^{40,41}$ and has been modified for performing the adsorption of $\mathrm{CH}_{3} \mathrm{I}$ on $\mathrm{Ag}^{0}$-Aerogel experiments. Figure 1 shows the schematic diagram of the modified adsorption system. 


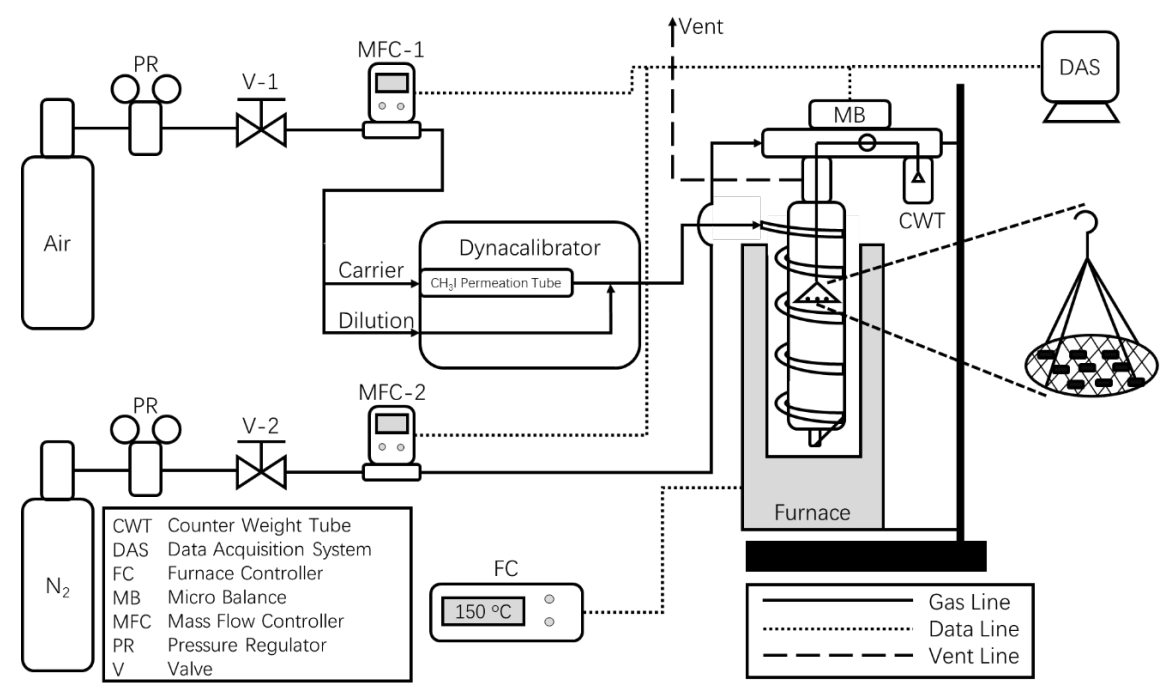

Figure 1. Schematic diagram of the continuous flow $\mathrm{CH}_{3} \mathrm{I}$ adsorption system

Dry air flowed through Dynacalibrator (VICI, Model 500), in which a permeation tube (VICI) was placed, as the carrier gas to generate $\mathrm{CH}_{3} \mathrm{I}$. The $\mathrm{CH}_{3} \mathrm{I}$ concentration was controlled by the specific permeation tube model and the temperature of the permeation chamber. $500 \mathrm{sccm}$ of gas mixture was preheated to 150 in the preheating coil wound around the adsorption column and then sent to the adsorption column (I.D. $=30$ $\mathrm{mm}$ ). In the adsorption column, one layer of $\mathrm{Ag}^{0}$-Aerogel pellets was placed on a tray and suspended under the microbalance. The microbalance has a variance of approximately $30 \mu \mathrm{g}$ and a sensitivity of $0.1 \mu \mathrm{g}$. When the $\mathrm{CH}_{3} \mathrm{I}$ vapor was absorbed by $\mathrm{Ag}^{0}$-Aerogel pellets, mass change was measured by the microbalance and saved by the data acquisition system. During the adsorption process, the temperature was controlled by the furnace controller and $\mathrm{N}_{2}$ was used as the protective gas for the microbalance system.

\section{Modeling}

Multiple gas-solid adsorption models have been used in explaining adsorption kinetics of $\mathrm{I}_{2}$ and Organic Iodides including Linear Driving Force Model (LDFM), Shrinking Core Model (SCM), Volume Reaction Model (VRM) and Pore Diffusion Model (PDM). ${ }^{16,18,38,42-46} \mathrm{I}_{2}$ adsorption on $\mathrm{Ag}^{0} \mathrm{Z}$ has been identified as the shrinking core process because the core shrinkage was observed by Nan. ${ }^{16}$ Shown in Figure 2, a similar process was observed in $\mathrm{CH}_{3} \mathrm{I}$ adsorption on $\mathrm{Ag}^{0}$-Aerogel by cutting a partially reacted pellet in half. The yellow area is the reacted $\mathrm{Ag}^{0}$-Aerogel and the black area is the unreacted core. Therefore, the shrinking core model was selected to model the adsorption kinetics. 


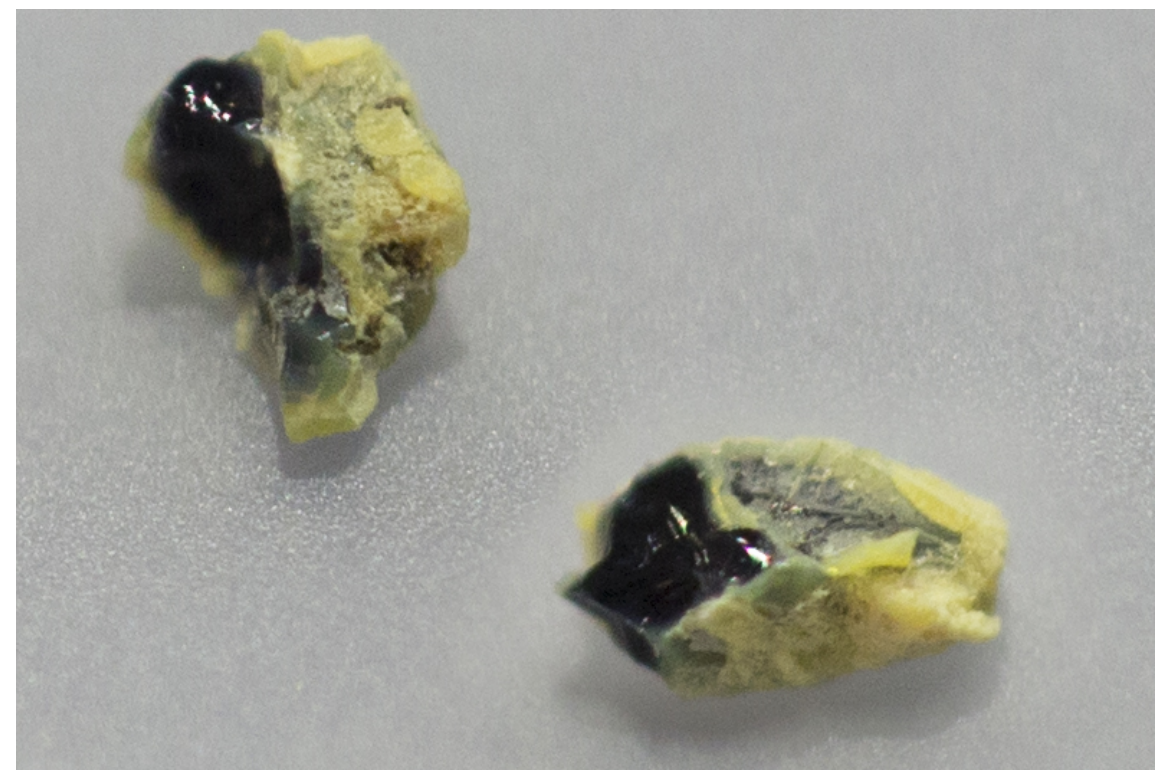

Figure 2. Shrinking core process observed in $\mathrm{CH}_{3} \mathrm{I}$ adsorption on $\mathrm{Ag}^{0}$-Aerogel, two cut halves of a partially reacted pellet

SCM was developed by Yagi and $\mathrm{Kunii}^{47}$ in 1955 and modified by Levenspiel ${ }^{48}$. It consists of a gas film diffusion term, pore diffusion term and reaction term. In a typical SCM gas-solid adsorption process, the adsorbate first reaches the pellet surface by diffusing through a gas film around the pellet. Then, the gas reacts with the adsorbent surface. When the adsorbent surface is fully reacted, the adsorbate diffuses into the pellet and reacts with the second layer of the adsorbent. Because the size of the unreacted core decreases as the adsorption proceeds, the model is named as 'shrinking core'. This model has been widely used in the nuclear waste treatment area including water adsorption on molecular sieves $3 \mathrm{~A}^{40}$, water adsorption on $\mathrm{Ag}^{0} \mathrm{Z}^{16,38}, \mathrm{I}_{2}$ adsorption on $\mathrm{Ag}^{0} \mathrm{Z}^{16,19}, \mathrm{CH}_{3} \mathrm{I}$ adsorption on $\mathrm{Ag}^{0} \mathrm{Z}^{18}$, etc.

SCM relates the time and adsorption mass by using 3 parts shown in Eq. 1:

where $q$ is average sorbate $\left(\mathrm{CH}_{3} \mathrm{I}\right)$ concentration $(\mathrm{mol} / \mathrm{g})$ at time $t(\mathrm{~s})$ and $q_{e}$ is equilibrium sorbate $\left(\mathrm{CH}_{3} \mathrm{I}\right)$ concentration $(\mathrm{mol} / \mathrm{g})$. For convenience, $q$ and $q_{e}$ are sometimes represented as 'mass uptake' and 'equilibrium mass uptake/adsorption capacity' in wt\%, which can be easily converted by the $\mathrm{CH}_{3} \mathrm{I}$ molar mass. $\tau_{1}$ ,$\tau_{2}$, and $\tau_{3}$ are gas film diffusion term, pore diffusion term, and $1^{\text {st }}$ order reaction term respectively. By assuming gas-solid reaction is $1^{\text {st }}$ order, $\tau_{1}, \tau_{2}$, and $\tau_{3}$ can be calculated by Eq. 2,3 and 4

where $R_{a}$ is radius of the pellet $(\mathrm{cm}), \rho_{\pi}$ is density of the pellet $\left(\mathrm{g} / \mathrm{cm}^{3}\right), C_{b}$ is bulk adsorbate $\left(\mathrm{CH}_{3} \mathrm{I}\right)$ concentration $\left(\mathrm{mol} / \mathrm{cm}^{3}\right), k_{f}$ is gas film mass transfer coefficient $(\mathrm{cm} / \mathrm{s}), D_{p}$ is pore diffusivity $\left(\mathrm{cm}^{2} / \mathrm{s}\right), k_{s}$ is $1^{\text {st }}$ order reaction rate constant $(\mathrm{cm} / \mathrm{s})$ and $b$ is stoichiometric coefficient of $\mathrm{Ag}$ in $\mathrm{Ag}-\mathrm{CH}_{3} \mathrm{I}$ reaction, which is 1.

To improve the SCM, the unnecessary $1^{\text {st }}$ order reaction assumption may be replaced by the $\mathrm{n}^{\text {th }}$ order reaction, which $\tau_{1}$ and $\tau_{2}$ remain the same and $\tau_{3}$ is replace by $\mathrm{n}^{\mathrm{th}}$ order reaction term $\tau_{3}{ }^{*}$ given in Eq. 5 :

where $n$ is reaction order and $k_{s}{ }^{*}$ is $\mathrm{n}^{\text {th }}$ order reaction rate constant $\left((\mathrm{cm} / \mathrm{s})[?]\left(\mathrm{mol} / \mathrm{cm}^{3}\right)^{1-\mathrm{n}}\right)$

To reduce the variables to be fitted in the model and increase the accuracy of the result, an alternative method of determining $k_{f}$ was used by Nan. ${ }^{16,19} k_{f}$ can be determined using Eq. $6-9 .{ }^{49-52}$

$S h, S c$, and Re are Sherwood number, Schmidt number, and Reynolds number respectively. $D_{A B}$ is the binary diffusion coefficient $\left(\mathrm{cm}^{2} / \mathrm{s}\right), T$ is temperature $(\mathrm{K}), P$ is pressure (bar), $M_{A B}$ is the average molecular weight of species $A, \mathrm{CH}_{3} \mathrm{I}$, and species $B$, air, and $\nu$ is the atomic diffusion volume $\left(\mathrm{cm}^{3}\right)$. For current 
experimental condition, $T=423 \mathrm{~K}, P=1 \mathrm{bar}, M_{A B}=48.12 \mathrm{~g} / \mathrm{mol},=52.63 \mathrm{~cm}^{3}$ and $=19.7 \mathrm{~cm}^{3} \cdot{ }^{50}$ The $D_{A B}$ determined using this method is approximately $0.196 \mathrm{~cm}^{2} / \mathrm{s}$, which is similar to the value of $0.207 \mathrm{~cm}^{2} / \mathrm{s}$ measured experimentally by Matsunaga et al. ${ }^{53}$

\section{Procedure description}

As mentioned above, the $\mathrm{CH}_{3} \mathrm{I}$ concentration in VOG is below $100 \mathrm{ppb}$. Measuring mass adsorbed at such low concentrations is beyond the capability of microbalances. More specifically, the mass uptake cannot be detected confidently by using microbalances in an acceptable time frame. Therefore, the $\mathrm{CH}_{3} \mathrm{I}$ concentrations used for adsorption were selected to be 113, 266, 1130 and 10400 ppbv. Other experimental conditions such as temperature and gas flow rate are selected base on previous studies. 150 / 423K was reported as the preferred experiment temperature for $\mathrm{I}_{2}$ and $\mathrm{CH}_{3} \mathrm{I}$ adsorption and has been widely used in multiple studies. ${ }^{16-18}$ The gas flow rate may impact the adsorption rate by varying superficial gas velocity and therefore changing $k_{f}$. Nan et al. ${ }^{19}$ indicated that no obvious impact was observed at $423 \mathrm{~K}$ for superficial velocity greater than $1.1 \mathrm{~m} / \mathrm{min}$. To satisfy this condition, the gas flow rate measured at room temperature is set to be approximately $500 \mathrm{~cm}^{3} / \mathrm{min}$. To prevent any significant concentration gradient caused by overlapping, one layer of $\mathrm{Ag}^{0}$-Aerogel pellets (0.1-0.2 $\mathrm{g}$ ) was placed in the tray suspended under the microbalance, shown in Figure 1.

At ppb level concentration, the adsorption rate of $\mathrm{CH}_{3} \mathrm{I}$ is significantly lower than that of ppm level adsorption. Therefore, the pellets must be dried carefully to prevent any misleading result caused by moisture loss during the $\mathrm{CH}_{3} \mathrm{I}$ adsorption. Over $150 \mathrm{~h}$ is required to air-dry $\mathrm{Ag}^{0}$-Aerogel, in other words, placing in the tray and flow dry air (Dew Point $=-70$ ) until no mass loss is observed. To accelerate this process, the $\mathrm{Ag}^{0}$-Aerogel was vacuum dried at 150 overnight using the degas function of a Surface Area and Porosity Analyzer (Micromeritics, ASAP 2020) and stored under $\mathrm{N}_{2}$ environment before conducting the adsorption experiments.

Unlike previous 10-50 ppm level adsorption studies ${ }^{16,18,19}$, reaching equilibrium is not practicable at ppb level. For example, based on experimental results and predictions, it may take over 3 years for $\mathrm{Ag}^{0}$-Aerogel to reach equilibrium at $1130 \mathrm{ppbv} \mathrm{CH}_{3} \mathrm{I}$ condition. Therefore, the adsorption experiments were stopped after a certain period instead of reaching equilibrium.

\section{Results}

\section{Adsorption Kinetics}

Four adsorption experiments with 113, 266, 1130 and 10400 ppbv $\mathrm{CH}_{3} \mathrm{I}$ in dry air were conducted. The concentrations were calculated from the data provided by the permeation tube manufacturer and confirmed by measuring the mass differences of the permeation tubes before and after the experiments. Approximately 288 hours adsorption data of 113, 266, 1130 and 10400 ppbv $\mathrm{CH}_{3} \mathrm{I}$ adsorption on $\mathrm{Ag}^{0}$-Aerogel are plotted in Figure 3. For 288 hours, mass uptakes reached 0.17, 0.91, 3.7 and 14.7 wt\% at 113, 266, 1130 and 10400 ppbv respectively. To eliminate the physically adsorbed $\mathrm{CH}_{3} \mathrm{I}$, the $\mathrm{Ag}^{0}$-Aerogel was left in the adsorption column and desorbed by stopping $\mathrm{CH}_{3} \mathrm{I}$ generation and flowing only dry air for $24 \mathrm{~h}$. During this desorption process, no significant mass losses were observed, indicating $\mathrm{CH}_{3} \mathrm{I}$ adsorption on $\mathrm{Ag}^{0}$-Aerogel was mostly chemisorption. Limited by the low mass uptake, 113 and 266 ppbv adsorption curve cannot be identified well in Figure 3 and a close view of 4 uptake curves is shown in Figure 4. 


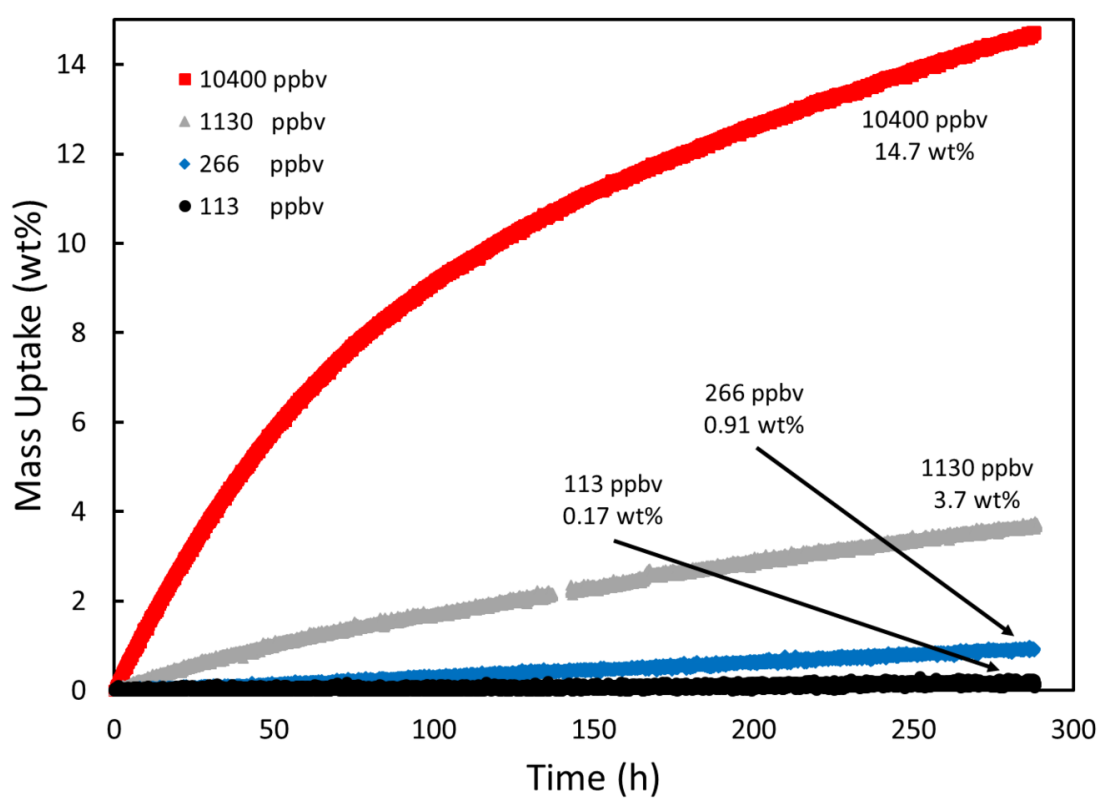

Figure 3. Uptake curves of $113,266,1130$ and 10400 ppbv $\mathrm{CH}_{3} \mathrm{I}$ adsorptions on $\mathrm{Ag}^{0}$-Aerogel for up to 288 hours.

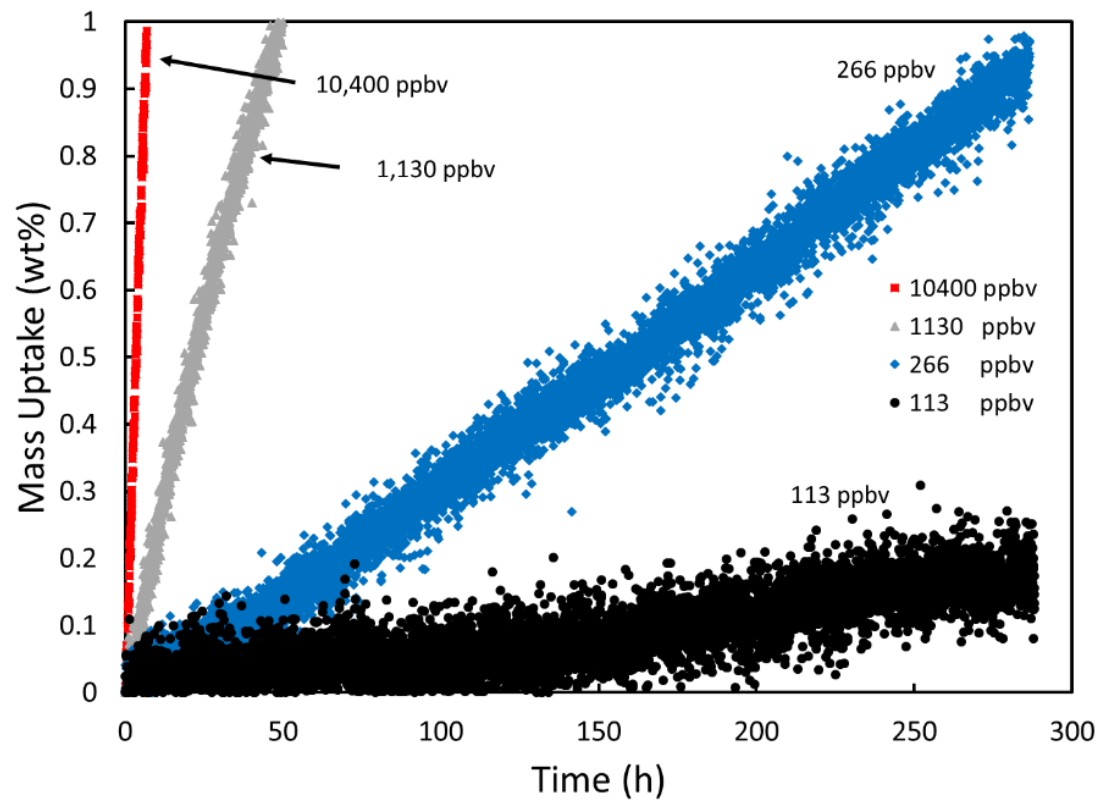

Figure 4. Closer view of uptake curves of 113, 266, 1130 and 10400 ppbv $\mathrm{CH}_{3} \mathrm{I}$ adsorptions on $\mathrm{Ag}^{0}$-Aerogel for up to 288 hours. 


\section{Model Fitting Result}

The $1^{\text {st }}$ order SCM was used to fit the kinetic data to determine $D_{p}$ and $k_{s}$ in Eq. 3 and 4 . To average the weights of different sections in the adsorption curves and increase the accuracy of data fitting, $t$ 's were rescaled by $\log _{10}$ before applying the least square regressions. More specifically, was used instead of, which $f$ is Eq. 1-4, subscript $i$ is the number of experimental data andexp is the indication of experimental data.

The model-fitting results and parameters are shown in Table $1 . k_{f}$, calculated theoretically to be $5.99 \mathrm{~cm} / \mathrm{s}$ by applying Eq. 6-9, kept constant at 4 different concentrations; $D_{p}$ and $k_{s}$ were determined in model fitting and $A A R D$ is calculated using, wheremodel indicates model fitting result and $N$ is the number of data points.

\begin{tabular}{llllll}
\hline $\begin{array}{l}\text { Concentration } \\
(\mathrm{ppbv})\end{array}$ & $\begin{array}{l}\text { Concentration } \\
(\mathrm{mol} / \mathrm{cm} 3)\end{array}$ & $k_{f}(\mathrm{~cm} / \mathrm{s})$ & $D_{p}\left(\mathrm{~cm}^{2} / \mathrm{s}\right)$ & $k_{s}(\mathrm{~cm} / \mathrm{s})$ & $A A R D(\%)$ \\
\hline 113 & $4.64 \times 10^{-12}$ & $5.99^{*}$ & $\mathrm{~N} / \mathrm{A}^{* *}$ & $5.43 \times 10^{-2}$ & 12.75 \\
266 & $1.09 \times 10^{-11}$ & $5.99^{*}$ & $4.50 \times 10^{-4}$ & $1.45 \times 10^{-1}$ & 0.27 \\
1130 & $4.64 \times 10^{-11}$ & $5.99^{*}$ & $4.70 \times 10^{-4}$ & $2.28 \times 10^{-1}$ & 1.02 \\
10400 & $4.27 \times 10^{-10}$ & $5.99^{*}$ & $4.56 \times 10^{-4}$ & $3.53 \times 10^{-1}$ & 0.26 \\
${ }^{*}$ Calculated & $*$ Calculated & & & & \\
theoretically & theoretically & & & \\
$* *$ Not & $* *$ Not & & & \\
determined & determined & & & \\
\hline
\end{tabular}

Table 1. Parameters and results of SCM fitting.

$D_{p}$ 's were determined to be $4.50 \times 10^{-4}, 4.70 \times 10^{-4}$ and $4.56 \times 10^{-4}$ for 266,1130 and 10400 ppbv respectively. For $113 \mathrm{ppbv} \mathrm{CH}_{3} \mathrm{I}$ adsorption, limited by the nature of low $\mathrm{CH}_{3} \mathrm{I}$ concentration, $D_{p}$ was not determined. As discussed previously, at low concentration, the $\mathrm{CH}_{3} \mathrm{I}$ has not consumed all $\mathrm{Ag}$ on the surface of $\mathrm{Ag}^{0}$-Aerogel pellet during the test time frame and therefore no significant pore diffusion was observed. The average $D_{p}$ was $4.59 \pm 0.102 \times 10^{-4} \mathrm{~cm}^{2} / \mathrm{s}$. Different from 3 similar $D_{p}$ 's, $k_{s}$ 's increase from $5.43 \times 10^{-2} \mathrm{~cm} / \mathrm{s}$ at $113 \mathrm{ppbv}$ to $3.53 \times 10^{-1} \mathrm{~cm} / \mathrm{s}$ at $10400 \mathrm{ppbv}$. The concentration-dependent $k_{s}$ is highly questionable. Theoretically, for a given reaction, the $k_{s}$ only depends on temperature and shall not change with the reactant concentration. ${ }^{54}$ Therefore, the orderly changed $k_{s}$ indicates an $\mathrm{n}^{\text {th }}$ order reaction instead of the assumed $1^{\text {st }}$ order.

\section{Discussion}

\section{$\mathrm{N}^{\text {th }}$ Order Shrinking Core Model}

The $\mathrm{n}^{\text {th }}$ order SCM cannot be used directly to fit an adsorption curve because $k_{s}{ }^{*} C_{b}{ }^{n}$ term in Eq. 5 contains two variables $\left(k_{s}{ }^{*} \& n\right)$ and one constant $\left(C_{b}\right)$. There exists an unlimited amount of combinations to yield the desired value. Instead, $k_{s}{ }^{*}$ and $n$ were determined by plotting $k_{s}(\mathrm{~cm} / \mathrm{s})$ and $C_{b}\left(\mathrm{~mol} / \mathrm{cm}^{3}\right)$ using Eq. 10 and 11 .

The reaction order and $\mathrm{n}^{\text {th }}$ order reaction constant were determined using Figure 5 and shown in Table 2. For $\mathrm{CH}_{3} \mathrm{I}-\mathrm{Ag}^{0}$-Aerogel adsorption system, $n=1.37$ and $k_{s}{ }^{*}=1287(\mathrm{~cm} / \mathrm{s})[?]\left(\mathrm{mol} / \mathrm{cm}^{3}\right)^{1-\mathrm{n}}$. As mentioned earlier, the SCM results can be applied to deep-bed adsorption analysis. However, keeping the $\mathrm{n}^{\text {th }}$ order reaction assumption may introduce certain difficulties in calculations. Therefore, Eq. 10 can be rewritten as Eq. 12 to calculate the $\mathrm{n}^{\text {th }}$-order-compensated, concentration-dependentpseudo $k_{s}$ 's $(\mathrm{cm} / \mathrm{s})$. 


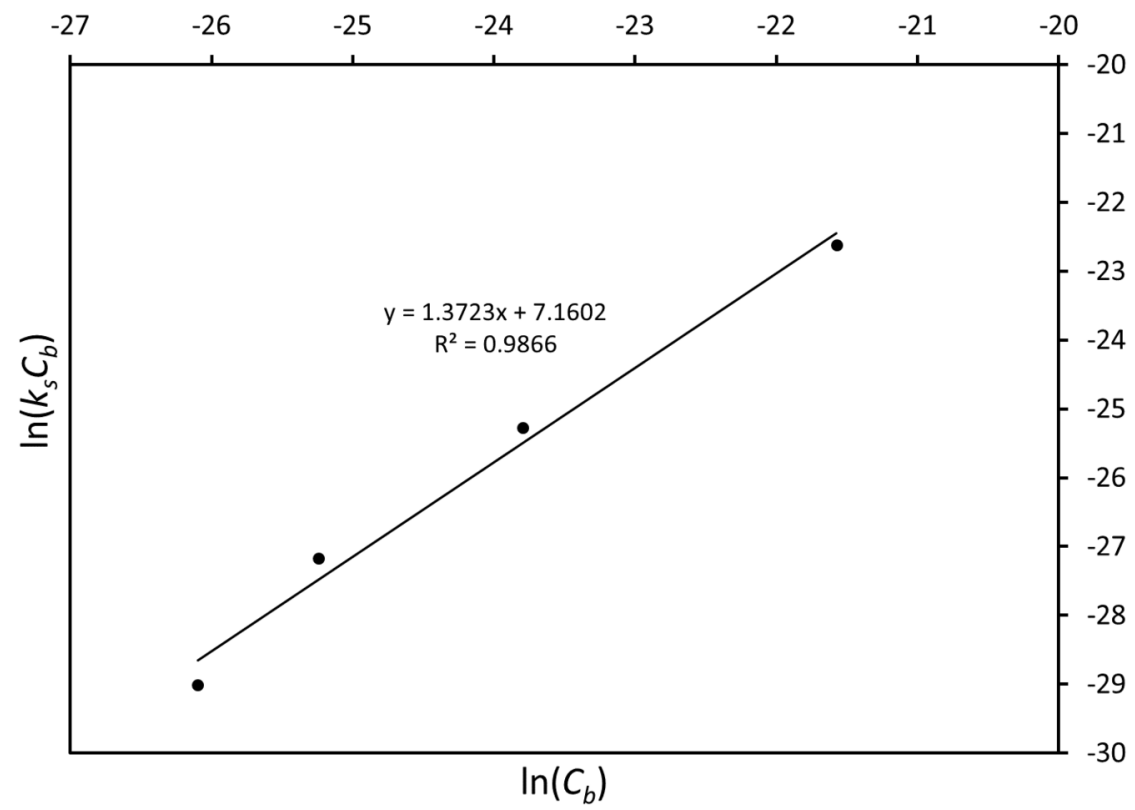

Figure 5. Reaction order plot, $\ln \left(C_{b}\right)$ vs. $\ln \left(k_{s} C_{b}\right)$

\begin{tabular}{llllll}
\hline Concentration $(\mathrm{ppbv})$ & $C_{b}\left(\mathrm{~mol} / \mathrm{cm}^{3}\right)$ & $k_{s}(\mathrm{~cm} / \mathrm{s})$ & $\ln \left(k_{s} C_{b}\right)$ & $\ln \left(C_{b}\right)$ & pseudo $k_{s}(\mathrm{~cm} / \mathrm{s})$ \\
\hline 113 & $4.64 \times 10^{-12}$ & $5.43 \times 10^{-2}$ & -29.01 & -26.10 & $7.76 \times 10^{-2}$ \\
266 & $1.09 \times 10^{-11}$ & $1.45 \times 10^{-1}$ & -27.17 & -25.24 & $1.07 \times 10^{-1}$ \\
1130 & $4.64 \times 10^{-11}$ & $2.28 \times 10^{-1}$ & -25.27 & -23.79 & $1.83 \times 10^{-1}$ \\
10400 & $4.27 \times 10^{-10}$ & $3.53 \times 10^{-1}$ & -22.62 & -21.57 & $4.18 \times 10^{-1}$ \\
$n=1.37$ & & & & & \\
$k_{s}{ }^{*}=1287(\mathrm{~cm} / \mathrm{s})[?]\left(\mathrm{mol} / \mathrm{cm}^{3}\right)^{1-\mathrm{n}}$ & $k_{s}{ }^{*}=1287(\mathrm{~cm} / \mathrm{s})[?]\left(\mathrm{mol} / \mathrm{cm}^{3}\right)^{1-\mathrm{n}}$ & & & & \\
\hline
\end{tabular}

Table 2. Parameters and results of determining reaction order

The reason for this fractional order reaction between $\mathrm{CH}_{3} \mathrm{I}$ and $\mathrm{Ag}^{0}$-Aerogel is not determined yet. This fractional-reaction order was also observed in other silver-containing materials. Zhou and White ${ }^{55}$ suggested that the desorption of organic products from $\mathrm{Ag}(111)$ surface changes the reaction order and Robb and Harriott ${ }^{56}$ indicated that the diffusion limitation in supported silver catalysts does. Therefore, the fractional reaction order maybe not only caused by the specific reaction mechanism but also the physical process.

\section{$\mathbf{N}^{\text {th }}$ Order SCM Examination and Application}

The effectiveness of the $\mathrm{n}^{\text {th }}$ order SCM can be demonstrated by comparing predictions made by the $\mathrm{n}^{\text {th }}$ order SCM and $1^{\text {st }}$ order SCM with average $k_{s}$, which the average $k_{s}=0.195 \mathrm{~cm} / \mathrm{s}$ was calculated by averaging $4 k_{s}$ 's directly. Figure 6 shows the prediction of 113 ppbv $\mathrm{CH}_{3} \mathrm{I}$ adsorption behavior generated by using $\mathrm{n}^{\text {th }}$ order SCM and $1^{\text {st }}$ order SCM with average $k_{s}$. Comparing with $1^{\text {st }}$ order SCM with average $k_{s}$, the $\mathrm{n}^{\text {th }}$ order SCM decreases AARD by approximately $175 \%$. The mass uptakes in 288 hours predicted by using $\mathrm{n}^{\text {th }}$ order SCM and $1^{\text {st }}$ order SCM with average $k_{s}$ were $0.24 \mathrm{wt} \%$ and $0.59 \mathrm{wt} \%$ respectively, where the measured mass uptake is approximately $0.17 \mathrm{wt} \%$. 


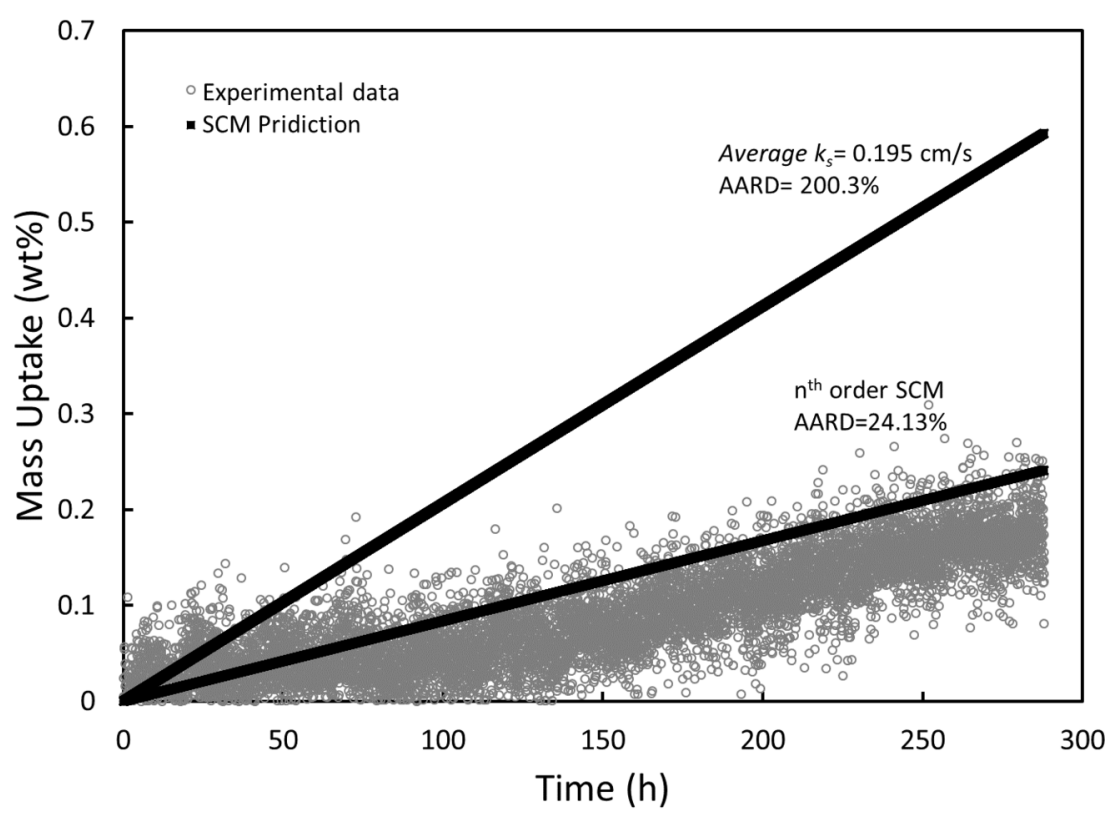

Figure 6. 113 ppbv $\mathrm{CH}_{3} \mathrm{I}$ on $\mathrm{Ag}^{0}$-Aerogel, $\mathrm{SCM}$ prediction using $\mathrm{n}^{\text {th }}$ order $\mathrm{SCM}$ and $1^{\text {st }}$ order $\mathrm{SCM}$ with average $k_{s}$.

With the developed $\mathrm{n}^{\text {th }}$ order SCM, the adsorption behavior can be predicted more accurately. Figure 7 shows the predicted behavior of 113, 266, 1130 and 10400 ppbv $\mathrm{CH}_{3} \mathrm{I}$ adsorption on $\mathrm{Ag}^{0}$-Aerogel at 150 using $\mathrm{n}^{\text {th }}$ order SCM. The capacity loss caused by dry air aging effect was not considered, which means $q_{e}=37$ wt $\%$ or $2.9 \times 10^{-3} \mathrm{~mol} / \mathrm{g}$, and other parameters are $k_{f}=5.99 \mathrm{~cm} / \mathrm{s}, D_{p}=4.59 \times 10^{-4} \mathrm{~cm}^{2} / \mathrm{s}, n=1.37$ and $k_{s}{ }^{*}$ $=1287(\mathrm{~cm} / \mathrm{s})[?]\left(\mathrm{mol} / \mathrm{cm}^{3}\right)^{1-\mathrm{n}}$. Based on the results, for $\mathrm{CH}_{3} \mathrm{I}$ adsorption on $\mathrm{Ag}^{0}$-Aerogel at 150 reaching equilibrium, $19 \mathrm{~K}$ days are required at $113 \mathrm{ppbv}$ condition, $7.6 \mathrm{~K}$ days at $266 \mathrm{ppbv}, 1.6 \mathrm{~K}$ days at $1130 \mathrm{ppbv}$ and 170 days at 10400 ppbv.

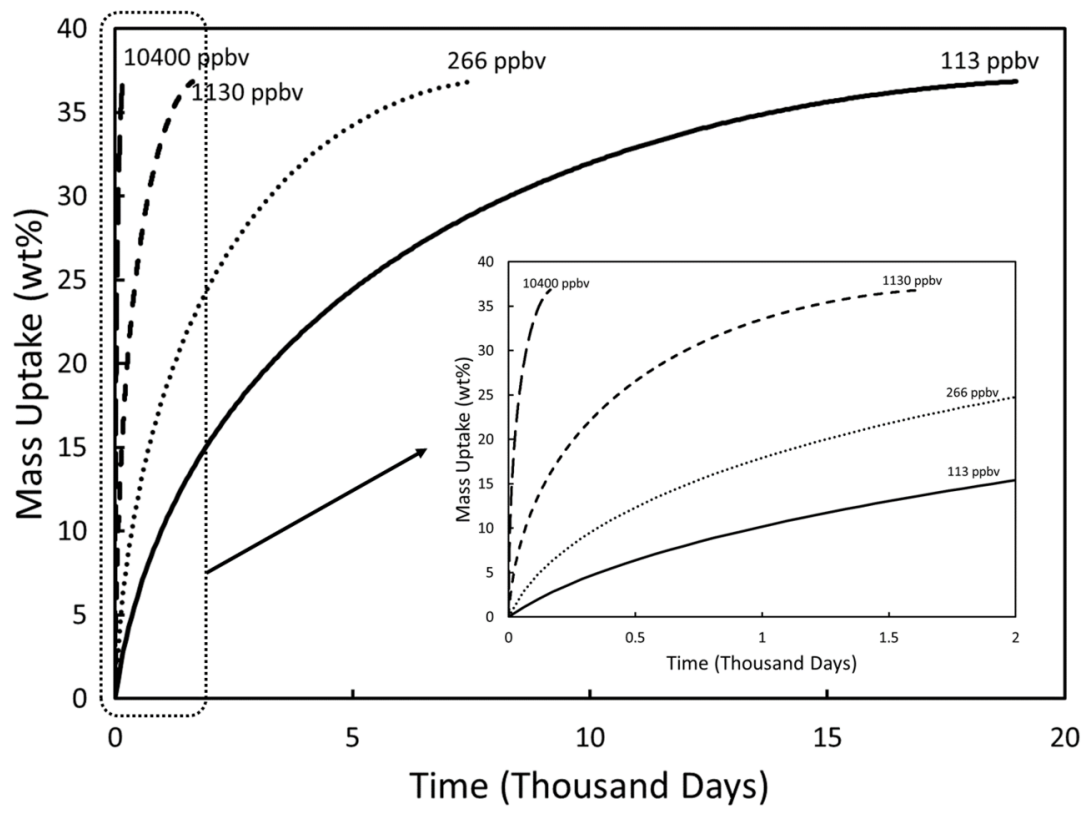


Figure 7. 113, 266, 1130 and 10400 ppbv $\mathrm{CH}_{3} \mathrm{I}$ adsorption behavior prediction using $\mathrm{n}^{\text {th }}$ order $\mathrm{SCM}$

\section{Rate-Controlling Step}

For further analysis and application of the SCM results, it is necessary to understand the rate-controlling step of the process. To determine how the $\mathrm{CH}_{3} \mathrm{I}-\mathrm{Ag}^{0}$-Aerogel adsorption is controlled, $\tau_{1}, \tau_{2}$, and $\tau_{3}$ at 4 different concentrations were calculated using Eq 2-4 with the determined parameters shown in Table 1. $\tau_{1}, \tau_{2}$, and $\tau_{3}$ are the partial adsorption equilibrium time contributed by the gas film diffusion, pore diffusion, and reaction term. More straightforwardly, the equilibrium time, $t_{e q}$, can be expressed as $t_{e q}$ $=\tau_{1}+\tau_{2}+\tau_{3}$. For the SCM, the control term can be represented by overall resistance ratio, $\tau_{\imath} / t_{e q}$, where $i=1,2$, or $3{ }^{38}$ Figure 8 shows the resistance contributions of pore diffusion term and reaction term, whereas the gas film diffusion term is less than $1 \%$ and not shown in the figure. It was found that the reaction resistance contribution decreases from $25 \%$ at $113 \mathrm{ppbv}$ to $6 \%$ at $10400 \mathrm{ppbv}$ and the pore diffusion resistance contribution increases accordingly. Generally, for a given adsorption system, the resistance contribution is independent of the concentration of the adsorbate. Therefore, the change shown in Figure 8 is due to the $\mathrm{n}^{\text {th }}$ order reaction which has been discussed previously.

The adsorption rate is determined by the process with the highest resistance. Visualized from Figure 8, the pore diffusion contributes the most among the gas film diffusion, pore diffusion, and reaction term, especially for high $\mathrm{CH}_{3} \mathrm{I}$ concentration. Therefore, the $\mathrm{CH}_{3} \mathrm{I}-\mathrm{Ag}^{0}$-Aerogel adsorption is identified as an 'overall' diffusion-controlled process. The overall process is diffusion-controlled, but at certain conditions, the process may not be controlled by diffusion, which will be discussed in the following section. Moreover, as the concentration decreased from 10400 to $113 \mathrm{ppbv}$, the ratio of reaction resistance contribution increases significantly, indicating that the $\mathrm{CH}_{3} \mathrm{I}-\mathrm{Ag}^{0}$-Aerogel adsorption may change from a pore diffusion-controlled to a reaction-controlled process if the concentration decreases substantially.

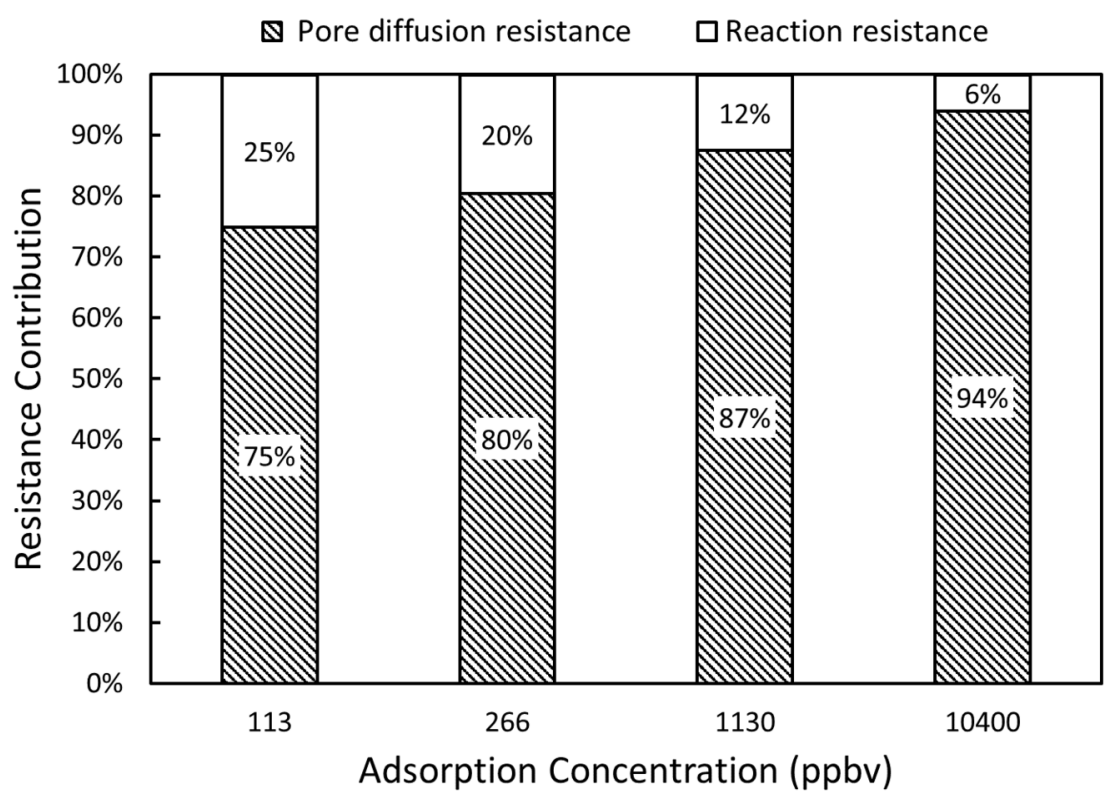

Figure 8. Resistance contributions of pore diffusion and reaction terms for $\mathrm{CH}_{3} \mathrm{I}-\mathrm{Ag}^{0}$-Aerogel adsorption at 113, 266, 1130 and 10400 ppbv.

Although the overall process is controlled by the pore diffusion of $\mathrm{CH}_{3} \mathrm{I}$, at VOG conditions, the rate determining step may vary because of the actual adsorption process. As mentioned above, in the VOG stream, 
the $\mathrm{CH}_{3} \mathrm{I}$ concentration is lower than $100 \mathrm{ppbv}$, more dilute than the low boundary of the current work, and the adsorption rate is extremely low. For example, at $113 \mathrm{ppbv}$, the prediction shows that the adsorption may not reach equilibrium in approximately 50 years if the capacity loss is neglected. Therefore, the actual active regions are only the initial parts of the adsorption curves. These regions correspond to the surface reaction between $\mathrm{CH}_{3} \mathrm{I}$ and $\mathrm{Ag}^{0}$-Aerogel, which are highly reaction-controlled. In this process, $\mathrm{CH}_{3} \mathrm{I}$ reacts with $\mathrm{Ag}$ on the surface of $\mathrm{Ag}^{0}$-Aerogel and only a limited amount of $\mathrm{CH}_{3} \mathrm{I}$ diffuses into the pellets. Quantitatively speaking, at VOG conditions, the $q / q_{e}$ term in Eq. 1 is much smaller than 1 and by specifying the $q / q_{e}$ values, the real-time contributions of diffusion term and reaction term can be calculated. For example, as Figure 9 shows, at $113 \mathrm{ppbv}$, the reaction term contributes approximately $62 \%$ at $q / q_{e}=0.2$ or $q=$ $7.4 \mathrm{wt} \%$, which approximately 600 days are required to reach this point. Additionally, within one year, the reaction term contribution is higher than $93 \%$ and the mass uptake is below $0.74 \mathrm{wt} \%$. Therefore, it is important to notice that although the overall adsorption process is controlled by the pore diffusion, at actual VOG conditions, the effect of pore diffusion to the uptake rate is minor in at least 1-2 years. To determine the $\mathrm{CH}_{3} \mathrm{I}-\mathrm{Ag}^{0}$-Aerogel adsorption behavior at low concentration conditions, the analysis should focus on the reaction rate instead of pore diffusivity.

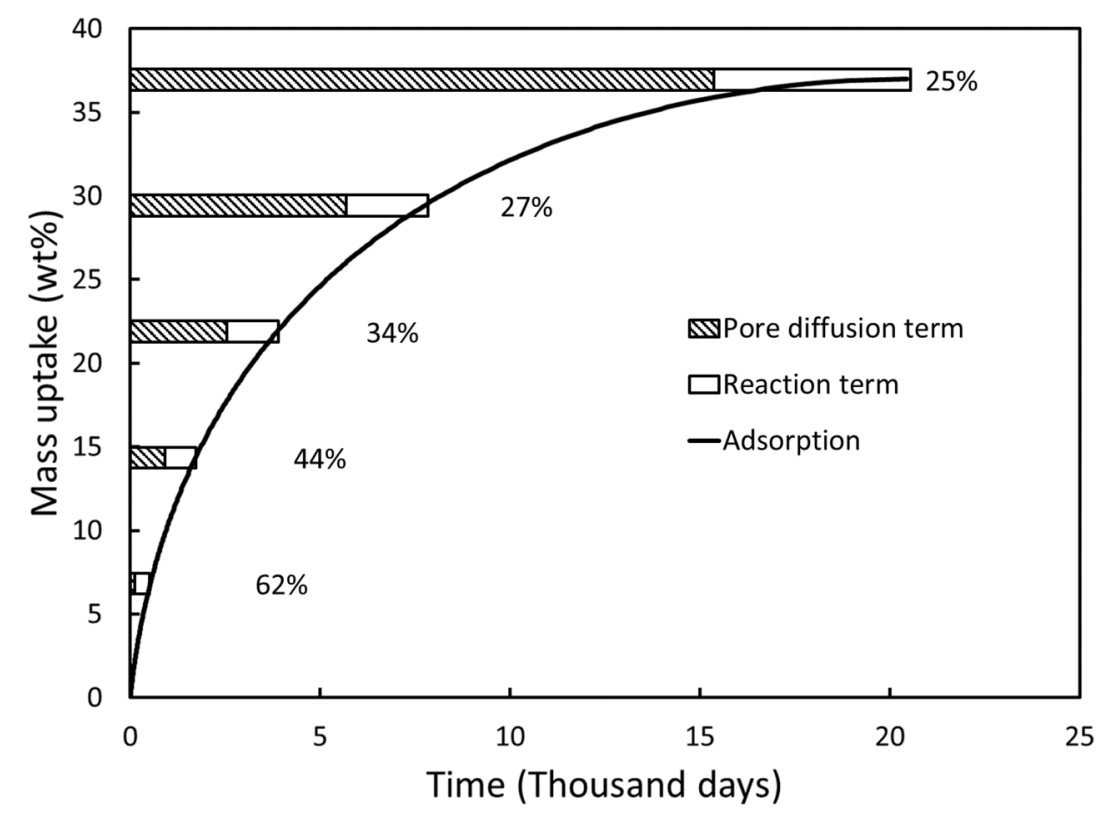

Figure 9. Real-time contribution of reaction term and pore diffusion term in $\mathrm{CH}_{3} \mathrm{I}-\mathrm{Ag}^{0}$-Aerogel adsorption at 113 ppbv (percentage represents reaction contribution).

Because the adsorption behavior at low concentration minorly depends on gas film diffusion and pore diffusion term, the SCM in Eq. 1 can be reduced to Eq. 13 and the mass uptake rate is given in Eq. 14 .

Since at the initial region, $t<<\tau_{3}$, Eq. 14 can be written as Eq. 15 for $\mathrm{n}^{\text {th }}$ order reaction.

Furthermore, by replacing $R_{a}$ and $\rho_{\pi}$, Eq. 15 becomes,

where $A$ is the specific surface area $\left(\mathrm{cm}^{2} / \mathrm{g}\right)$ of the material. This result indicates that at VOG conditions, the initial part, the only region need be considered, of $\mathrm{n}^{\text {th }}$ order SCM reduces to a simple $\mathrm{n}^{\text {th }}$ order surface reaction with a constant uptake rate, which can be demonstrated by 113 and 266 ppbv adsorption curves in Figure 3 and Figure 4. However, to increase the adsorption efficiency, simply increasing the surface area by reducing the diameter may not be applicable. The surface reaction condition may not hold due to the change of flow regime caused by fine pellets. 


\section{Conclusion}

The kinetic data of $\mathrm{CH}_{3} \mathrm{I}$ adsorption on $\mathrm{Ag}^{0}$-Aerogel at 150 were obtained using the continuous flow adsorption system. The $\mathrm{CH}_{3} \mathrm{I}$ concentrations were 113, 266, 1130 and 10400 ppbv. Because the corresponding shrinking core process was observed, the shrinking core model was applied to determine the gas film diffusivity, pore diffusivity and reaction rate constant. The $1^{\text {st }}$ order reaction was originally assumed. The well-agreed pore diffusivities were determined in three of the total four trails. The average value was 4.59 $\pm 0.102 \times 10^{-4} \mathrm{~cm}^{2} / \mathrm{s}$. Orderly increasing reaction rate constants were observed and, therefore, the modified $\mathrm{n}^{\text {th }}$ order SCM was selected for analysis.

The reaction order of $\mathrm{CH}_{3} \mathrm{I}-\mathrm{Ag}^{0}$-Aerogel adsorption was calculated to be approximately 1.37 and the reaction rate constant was approximately $1287(\mathrm{~cm} / \mathrm{s})[?]\left(\mathrm{mol} / \mathrm{cm}^{3}\right)^{1-n}$. This $\mathrm{n}^{\text {th }}$ order SCM effectively increases the accuracy of adsorption behavior prediction. Using $\mathrm{n}^{\text {th }}$ order SCM instead of $1^{\text {st }}$ order SCM, the AARD of 113 ppbv adsorption behavior prediction decreases from $200.3 \%$ to $24.13 \%$. Furthermore, the overall adsorption behaviors at 113, 266, 1130 and $10400 \mathrm{ppbv}$ were predicted. It requires more than 50 years for $\mathrm{Ag}^{0}$-Aerogel reach to equilibrium at $113 \mathrm{ppbv}$ condition if the capacity loss due to dry air aging effects is not considered.

The rate-controlling step of $\mathrm{CH}_{3}-\mathrm{Ag}^{0}$-Aerogel adsorption was identified by plotting the resistance of different rate-dependent terms. Although the overall adsorption process is controlled by pore diffusion, the surface reaction between $\mathrm{CH}_{3} \mathrm{I}$ and $\mathrm{Ag}$ is more crucial at VOG conditions. The nature of low concentration in VOG streams $\left(C_{b}<100 \mathrm{ppbv}\right)$ limits the adsorption from a full $\mathrm{n}^{\text {th }}$ order SCM to a surface reaction. To increase the adsorption efficiency, decreasing the size of pellets is a theoretically applicable method. However, the detailed solution still requires further studies in deep-bed adsorption. As replacing the $1^{\text {st }}$ order SCM by $n^{\text {th }}$ order SCM, the accuracy of adsorption behavior prediction at VOG conditions was increased significantly. The parameters determined can be widely applied to the deep-bed adsorption system design of the off-gas treatment in the nuclear fuel reprocessing process.

\section{Acknowledgement}

This research was funded by the Nuclear Energy University Program of the U.S. Department of Energy, Office of Nuclear Energy (Grant No. DE-NE0008761)

\section{Literature Cited}

1. Lenzen M. Life cycle energy and greenhouse gas emissions of nuclear energy: A review. Energy Conversion and Management.2008;49(8):2178-2199.

2. Wei M, Patadia S, Kammen DM. Putting renewables and energy efficiency to work: How many jobs can the clean energy industry generate in the US? Energy Policy. 2010;38(2):919-931.

3. Menyah K, Wolde-Rufael Y. CO2 emissions, nuclear energy, renewable energy and economic growth in the US. Energy Policy.2010;38(6):2911-2915.

4. Daryl H. Methods of Gas Phase Capture of Iodine from Fuel Reprocessing Off-Gas: A Literature Survey. Techincal Report No. INL/EXT-07-12299. Idaho National Laboratory, Idaho Falls, ID. 2007

5. Purkayastha BC, Martin GR. The yields of 129I in natural and in neutron-induced fission of uranium. Canadian Journal of Chemistry. 1956;34(3):293-300.

6. Bruffey SH, Jubin RT, Jordan JA. Capture of Elemental and Organic Iodine from Dilute Gas Streams by Silver-exchanged Mordenite.Procedia Chemistry. 2016;21:293-299.

7. Bruffey SH, Jubin RT. Iodine Adsorption by Ag-Aerogel under Prototypical Vessel Off-Gas Conditions. Techincal Report No. ORNL/TM-2016-417. Oak Ridge National Laboratory (ORNL), Oak Ridge, TN. 2016 
8. EPA. Environmental radiation protection standards for nuclear power operations (40 CFR Part 190). US Environmental Protection Agency, Washington, DC. 2010

9. NRC. NRC regulations title 10 - code of federal regulations, Part 20-standards for protection against radiation. US Nuclear Regulatory Commission, Washington, DC. 2019

10. EPA. National Emission Standards for Hazardous Air Pollutants: Radionuclides (40 CFR Part 61). US Environmental Protection Agency, Washington, DC. 2019

11. Strachan DM, Bruffey SH, Spencer BB, et al. A literature survey to identify potentially problematic volatile iodine-bearing species present in off-gas streams. Techincal Report No. ORNL-SPR-2015/290. Oak Ridge National Laboratory (ORNL), Oak Ridge, TN. 2015

12. Bruffey SH, Jubin RT, Jordan JA. Quantify the Extent of Physisorption on Silver Based Sorbents under VOG Conditions. Techincal Report No. ORNL/SPR-2018/1066. Oak Ridge National Lab.(ORNL), Oak Ridge, TN. 2018

13. Jubin RT, Bruffey SH, Spencer BB. Performance of Silver-exchanged Mordenite for Iodine Capture under Vessel Off-gas Conditions. Oak Ridge National Lab.(ORNL), Oak Ridge, TN 2015

14. Jubin RT, Bruffey SH, Jordan JA. Performance of Silver-Exchanged Mordenite and Silver-Functionalized Silica-Aerogel Under Vessel Off-gas Conditions. Techincal Report No. ORNL/SR-2017/477. Oak Ridge National Lab(ORNL), Oak Ridge, TN. 2017

15. Matyaš J, Fryxell G, Busche B, Wallace K, Fifield L. Functionalised silica aerogels: Advanced materials to capture and immobilise radioactive iodine. Paper presented at: Ceramic Engineering and Science Proceedings. 2011

16. Nan Y. Adsorption of Iodine and Water on Silver-Exchanged Mordenite [Dissertation]. Sryacuse: Syracuse University. 2017

17. Soelberg NR, Watson TL. FY-2016 Methyl Iodide Higher NOx Adsorption Test Report. Techincal Report No. INL/EXT-16-40087. Idaho National Laboratory, Idaho Falls, ID. 2016

18. Jubin RT. The mass transfer dynamics of gaseous methyl-iodide adsorption by silver-exchanged sodium mordenite [Dissertation]. Knoxville: The University of Tennessee. 1994

19. Nan Y, Tavlarides LL, DePaoli DW. Adsorption of iodine on hydrogen-reduced silver-exchanged mordenite: Experiments and modeling. AIChE Journal. 2017;63(3):1024-1035.

20. Ali M, Yan C, Sun Z, Gu H, Wang J, Mehboob K. Iodine removal efficiency in non-submerged and submerged self-priming venturi scrubber.Nuclear Engineering and Technology. 2013;45(2):203-210.

21. Ali M, Yan C, Sun Z, Gu H, Wang J. Study of iodine removal efficiency in self-priming venturi scrubber. Annals of Nuclear Energy. 2013;57:263-268.

22. Gulhane NP, Landge AD, Shukla DS, Kale SS. Experimental study of iodine removal efficiency in self-priming venturi scrubber. Annals of Nuclear Energy. 2015;78:152-159.

23. Jubin RT, Bruffey SH, Jordan JA. Performance of Silver-Exchanged Mordenite and Silver-Functionalized Silica-Aerogel Under Vessel Off-gas Conditions. Techincal Report No. ORNL/TM-2017/447. Oak Ridge National Lab. (ORNL), Oak Ridge, TN (United States). 2017

24. Bruffey SH, Jubin RT, Jordan JA. Organic Iodine Adsorption by AgZ under Prototypical Vessel Off-Gas Conditions. Techincal Report No. ORNL/TM-/568. Oak Ridge National Lab(ORNL), Oak Ridge, TN. 2016

25. Soelberg N, Watson T. Phase 1 Methyl Iodide Deep-Bed Adsorption Tests. Techincal Report No. INL/EXT-14-32917. Idaho National Laboratory, Idaho Falls, ID. 2014 
26. Soelberg NR, Watson TL. FY-2015 Methyl Iodide Deep-Bed Adsorption Test Report. Techincal Report No. INL/EXT-15-36817. Idaho National Laboratory, Idaho Falls, ID. 2015

27. Strachan DM, Chun J, Matyas J, et al. Summary Report on the Volatile Radionuclide and Immobilization Research for FY2011 at PNNL. Techincal Report No. PNNL-20807. Pacific Northwest National Laboratory, Richland, WA. 2011

28. Soelberg N, Watson T. Deep Bed Adsorption Testing using Silver-Functionalized Aerogel. Techincal Report No. INL/EXT-12-26522. Idaho National Laboratory, Idaho Falls, ID. 2012

29. Soelberg N, Watson T. Iodine Sorbent Performance in FY 2012 Deep Bed Tests. Techincal Report No. INL/EXT-12-27075. Idaho National Laboratory, Idaho Falls, ID. 2012

30. Scheele RD, Burger LL, Matsuzaki CL. Methyl iodide sorption by reduced silver mordenite. Techincal Report No. PNNL-4489. Pacific Northwest National Laboratory, Richland, WA. 1983

31. Zhou XL, Solymosi F, Blass PM, Cannon KC, White JM. Interactions of methyl halides (Cl, Br and I) with $\operatorname{Ag}(111)$. Surface Science.1989;219(1):294-316.

32. Fogler HS. Elements of chemical reaction engineering.Prentice Hall. 2016.

33. Jena PR, De S, Basu JK. A generalized shrinking core model applied to batch adsorption. Chemical Engineering Journal.2003;95(1):143-154.

34. Parisi DR, Laborde MA. Modeling of counter current moving bed gas-solid reactor used in direct reduction of iron ore. Chemical Engineering Journal. 2004;104(1):35-43.

35. Matyáš J, Fryxell GE, Robinson MJ. Characterization of Dry-Air Aged Granules of Silver-Functionalized Silica Aerogel. Techincal Report No. FCRD-SWF-2012-000214. Pacific Northwest National Laboratory, Richland, WA. 2012

36. Matyáš J, Robinson MJ, Fryxell GE. The effect of temperature and uniaxial pressure on the densification behavior of silica aerogel granules. Ceramic Materials for Energy Applications II.2012;33:121-132.

37. Jordan JA, Jubin RT. Stability of Tritium and Iodine Sorbents under Tritium-Pretreatment Off-Gas Conditions. Techincal Report No. ORNL/SR-2017/162. Oak Ridge National Lab(ORNL), Oak Ridge, TN. 2017

38. Nan Y, Liu J, Tang S, Lin R, Tavlarides LL. Silver-Exchanged Mordenite for Capture of Water Vapor in Off-Gas Streams: A Study of Adsorption Kinetics. Industrial \&5 Engineering Chemistry Research. 2018;57(3):1048-1058.

39. Nan Y, Lin R, Liu J, et al. Adsorption Equilibrium and Modeling of Water Vapor on Reduced and Unreduced Silver-Exchanged Mordenite.Industrial \& Engineering Chemistry Research.2017;56(28):8095-8102.

40. Lin R, Liu J, Nan Y, DePaoli DW, Tavlarides LL. Kinetics of Water Vapor Adsorption on Single-Layer Molecular Sieve 3A: Experiments and Modeling. Industrial 6 Engineering Chemistry Research.2014;53(41):16015-16024.

41. Lin R, Ladshaw A, Nan Y, et al. Isotherms for Water Adsorption on Molecular Sieve 3A: Influence of Cation Composition. Industrial $\&$ Engineering Chemistry Research. 2015;54(42):10442-10448.

42. Ruthven DM. Principles of adsorption and adsorption processes. John Wiley \& Sons. 1984.

43. Crank J. The mathematics of diffusion. Oxford university press. 1979.

44. Ruckenstein E, Vaidyanathan AS, Youngquist GR. Sorption by solids with bidisperse pore structures. Chemical Engineering Science.1971;26(9):1305-1318.

45. Ramachandran PA, Doraiswamy LK. Modeling of noncatalytic gas-solid reactions. AIChE Journal. 1982;28(6):881-900. 
46. Ramachandran PA, Kulkarni BD. Approximate analytical solution to Gas-Solid noncatalytic reaction problems. Industrial \& Engineering Chemistry Process Design and Development.1980;19(4):717-719.

47. Yagi S, Kunii D. Studies on combustion of carbon particles in flames and fluidized beds. Symposium (International) on Combustion.1955;5(1):231-244.

48. Levenspiel O. Chemical Reaction Engineering. New York: John Wiley \& Sons. 1972.

49. Ranz WE, Marshall WR. Evaporation from drops. Chem eng prog.1952;48(3):141-146.

50. Fuller EN, Ensley K, Giddings JC. Diffusion of halogenated hydrocarbons in helium. The effect of structure on collision cross sections. The Journal of Physical Chemistry.1969;73(11):3679-3685.

51. Fuller EN, Giddings JC. A Comparison of Methods for Predicting Gaseous Diffusion Coefficients. Journal of Chromatographic Science. 1965;3(7):222-227.

52. Fuller EN, Schettler PD, Giddings JC. A New Method for Prediction of Binary Gas-Phase Diffusion Coefficients. Industrial \& Engineering Chemistry. 1966;58(5):18-27.

53. Matsunaga N, Hori M, Nagashima A. Gaseous diffusion coefficients of methyl bromide and methyl iodide into air, nitrogen, and oxygen.Heat Transfer-Asian Research. 2009;38(6):361-369.

54. Arrhenius S. Über die Dissociationswärme und den Einfluss der Temperatur auf den Dissociationsgrad der Elektrolyte. Zeitschrift für physikalische Chemie. 1889;4(1):96-116.

55. Zhou XL, White JM. Thermal decomposition of C2H5I on Ag(111).Catalysis Letters. 1989;2(6):375-384.

56. Robb DA, Harriott P. The kinetics of methanol oxidation on a supported silver catalyst. Journal of Catalysis.1974;35(2):176-183. 